\title{
Technical Note: VUV photodesorption rates from water ice in the 120-150 K temperature range - significance for Noctilucent Clouds
}

\author{
M. Yu. Kulikov ${ }^{1}$, A. M. Feigin ${ }^{1}$, S. K. Ignatov ${ }^{2}$, P. G. Sennikov ${ }^{3,1}$, Th. Bluszcz ${ }^{4}$, and O. Schrems ${ }^{4}$ \\ ${ }^{1}$ Institute of Applied Physics of the Russian Academy of Science, 46 Ulyanov Str., 603950, Nizhny Novgorod, Russia \\ ${ }^{2}$ Lobachevsky State University of Nizhny Novgorod, 23 Gagarin Ave., 603950, Nizhny Novgorod, Russia \\ ${ }^{3}$ Institute of Chemistry of High-Purity Substances of the Russian Academy of Sciences, 49 Tropinin St., 603950, \\ Nizhny Novgorod, Russia \\ ${ }^{4}$ Alfred Wegener Institute for Polar and Marine Research, Am Handelshafen 12, 27570 Bremerhaven, Germany
}

Received: 12 August 2010 - Published in Atmos. Chem. Phys. Discuss.: 1 October 2010

Revised: 18 February 2011 - Accepted: 21 February 2011 - Published: 25 February 2011

\begin{abstract}
Laboratory studies have been carried out with the aim to improve our understanding of physicochemical processes which take place at the water ice/air interface initiated by solar irradiation with a wavelength of $121.6 \mathrm{~nm}$. It was intended to mimic the processes of ice particles characteristic of Noctilucent Clouds (NLCs). The experimental set-up used includes a high-vacuum chamber, a gas handling system, a cryostat with temperature controller, an FTIR spectrometer, a vacuum ultraviolet hydrogen lamp, and a microwave generator. We report the first results of measurements of the absolute photodesorption rate (loss of substance due to the escape of photoproducts into gas phase) from thin (20-100 nm) water ice samples kept in the temperature range of $120-150 \mathrm{~K}$. The obtained results show that a flow of photoproducts into the gas phase is considerably lower than presumed in the recent study by Murray and Plane (2005). The experiments indicate that almost all photoproducts remain in the solid phase, and the principal chemical reaction between them is the recombination reaction $\mathrm{H}+\mathrm{OH} \rightarrow \mathrm{H}_{2} \mathrm{O}$ which is evidently very fast. This means that direct photolysis of mesospheric ice particles seems to have no significant impact on the gas phase chemistry of the upper mesosphere.
\end{abstract}

\section{Introduction}

Noctilucent Clouds (NLCs) are the highest clouds of the Earth's atmosphere. They are formed during summer at middle to high latitudes in an altitude range between 80 and $90 \mathrm{~km}$ when the air temperature drops below $150 \mathrm{~K}$ (Gadsden

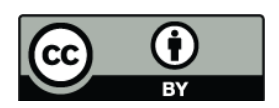

Correspondence to: M. Yu. Kulikov (kulm@appl.sci-nnov.ru) and Schröder, 1989; Thomas, 1991; Lübken, 1999). NLC features are important and sensitive indicators of global climate change, anthropogenic influence on atmospheric composition, and dynamical processes in the mesosphere - lower thermosphere altitudes. Seasonal and spatial occurrence zones of NLCs are in a good correlation with particularities of the so-called polar mesosphere summer echoes (Thomas et al., 1989; Thayer et al., 2003; von Zahn and Berger, 2003). In spite of the fact that the clouds were already discovered in the nineteenth century (Jesse, 1885), many processes of their formation and spatiotemporal evolution are still poorly understood because NLCs are rather far away from both, the ground-based and satellite instruments of atmospheric sounding. Only recently, Hervig et al. (2001) presented the first direct experimental confirmation of Alfred Wegener's idea (1912) that particles of NLCs consist primarily of water ice and are formed as a result of water vapour condensation ${ }^{1}$.

It is well known that water vapour is one of the most important trace gases of the upper mesosphere (e.g., Brasseur and Solomon, 1986). In particular, the photodissociation of water vapour by solar ultraviolet radiation with the wavelength of $121.6 \mathrm{~nm}$ (known as the Lyman- $\alpha$ line) is the principal source for the family of odd hydrogen $\left(\mathrm{HO}_{\mathrm{x}}=\mathrm{H}\right.$ $+\mathrm{OH}+\mathrm{HO}_{2}$ ). Gas-phase reactions with participation of these components represent the main sink for the components of the family of odd oxygen $\left(\mathrm{O}_{\mathrm{x}}=\mathrm{O}\left({ }^{1} \mathrm{D}\right)+\mathrm{O}\left({ }^{3} \mathrm{P}\right)+\mathrm{O}_{3}\right)$. Therefore, as water vapour concentration grows, daily concentration of $\mathrm{O}_{\mathrm{x}}$ decreases and vice versa. Recently, Murray and Plane (2005) noticed that photolysis of $\mathrm{H}_{2} \mathrm{O}$ molecules contained in the solid phase also takes place and showed that

\footnotetext{
${ }^{1}$ For more details about the history of the discovery and investigations of NLCs please see reviews by Gadsden and Schröder (1989) and Thomas (1991).
}

Published by Copernicus Publications on behalf of the European Geosciences Union. 
photochemical processes with participation of NLC particles, may in principle influence the chemistry of the upper mesosphere as an additional source of $\mathrm{HO}_{\mathrm{x}}$. Indeed, the solar Lyman- $\alpha$ photons penetrate into particles of NLCs and are absorbed essentially by $\mathrm{H}_{2} \mathrm{O}$ molecules of the ice particles having typical mean radii of some tens nm (e.g., von Cossart et al., 1999) comparable with the attenuation depth $(\sim 45 \mathrm{~nm}$, Warren, 1984) of $10.2 \mathrm{eV}$ photons in water ice. Moreover, the calculations by Murray and Plane showed that Mie absorption efficiency at $121.6 \mathrm{~nm}$ for spherical ice particles with radii larger than $30 \mathrm{~nm}$ is close to unity. The products $(\mathrm{H}$ and $\mathrm{OH}$ ) of the photolysis of water ice may volatilise leading to an enhancement of $\mathrm{HO}_{\mathrm{x}}$ concentration in the gas phase with a corresponding increase in $\mathrm{O}_{\mathrm{x}}$ removal. Murray and Plane (2005) performed numerical analyses of the impact of ice photolysis on the evolution of $\mathrm{O}$ concentration distribution in the upper summer mesosphere, assuming a realistic distribution of ice particles. It was shown that the effect is insignificant at night (because there is no irradiation) and is most pronounced during daytime when $\mathrm{O}$ concentration may decrease (relative to the unperturbed level) several fold at the heights of cloud existence. However, in this model study Murray and Plane considered the upper limit of photodesorption rates from particles of NLCs according to which each Lyman- $\alpha$ photon absorbed by a $\mathrm{H}_{2} \mathrm{O}$ molecule in the ice results in the immediate ejection of one $\mathrm{H}$ atom and one $\mathrm{OH}$ radical into gas phase. Therefore, these authors justly pointed out the need of laboratory measurements of $\mathrm{H}$ and $\mathrm{OH}$ yield from a thin ice film or another analog of small ice particles under temperatures pertinent to the summer mesosphere. It should be noted that release of these photoproducts (and some others: $\left.\mathrm{H}_{2}, \mathrm{O}\left({ }^{3} \mathrm{P}\right), \mathrm{O}\left({ }^{1} \mathrm{D}\right), \mathrm{H}_{2} \mathrm{O}\right)$ from VUV (157 and $193 \mathrm{~nm}$ ) irradiated water ice at high temperatures $(90$ $140 \mathrm{~K}$ ) were directly observed in the works by Yabushita et al. (2008a, b) and Hama et al. (2009a, b, c, 2010). However, these studies do not provide information about quantum yields of photoproducts and, therefore, do not give an answer to the question addressed by Murray and Plane (2005). Before these works, Westley et al. (1995a, b) measured desorption of photoproducts during Lyman- $\alpha$ irradiation of thick $(500 \mathrm{~nm})$ water ice samples at $T=35-100 \mathrm{~K}$ by using a quartz crystal resonator microbalance and mass - spectroscopy. They found out that most of the desorbed species were water molecules and values of photodesorption yield $Y_{0}$ (number of $\mathrm{H}_{2} \mathrm{O}$ molecules desorbed per incident photon) were essentially less than 1 molecule photon ${ }^{-1}$. In particular, the maximal value of $Y_{0} \sim 8 \times 10^{-3}$ molecule photon $^{-1}$ obtained at $T=100 \mathrm{~K}$ corresponded approximately to the probability of desorption from the topside molecular layer of the ice. Watanabe et al. (2000) carried out mass - spectroscopy experiments on the formation of $\mathrm{D}_{2}$ molecules from amorphous thin (thickness 4 and $12 \mathrm{~nm}$ ) $\mathrm{D}_{2} \mathrm{O}$ ice samples by VUV irradiation (126 and $172 \mathrm{~nm}$ ) at $12 \mathrm{~K}$. According to their results, only a small fraction of the total $\mathrm{D}_{2}$ photoproducts was released into gas-phase at the low temperature. Also they determined the cross section for the photodestruction of $\mathrm{D}_{2} \mathrm{O}$ which was found out to be close to the results gotten by Westley et al. (1995a, b) for water ice.

This note reports results of the first measurements of the absolute photodesorption rate (loss of substance due to the escape of photoproducts into gas phase) from thin (20$100 \mathrm{~nm}$ ) water ice samples in the temperature range of 120 $150 \mathrm{~K}$.

\section{Experimental details}

\subsection{Apparatus}

The experimental set-up consists of a closed-cycle He refrigerator (Leybold ROK 10-300) and a Fourier Transform Infrared Spectrometer (Bruker IFS 66v). The apparatus comprises a high-vacuum chamber with a volume of about $2000 \mathrm{~cm}^{3}$ (Fig. 1) pumped continuously by a turbomolecular pump system (Leybold-Heraeus) securing high vacuum in the chamber down to the $10^{-8}$ mbar range. Inside the chamber at the cold end of the cryostat there is a vertically mounted aluminium mirror $(2.5 \times 4 \mathrm{~cm}$ in size $)$ as a substrate whose temperature is precisely regulated by a temperature controller (Lake Shore, model 340). The temperature can be selected in the 10-300 K range. The oxygen (Air Liquide 5.5 $(\geq 99.9995 \mathrm{Vol} \%))$ or water samples are deposited onto the cold mirror by means of a gas-inlet system equipped with needle valves which allow controlling the deposition rate. The upper part of the high vacuum chamber has three ports, two of which are equipped with $\mathrm{MgF}_{2}$ (5 mm thick) input and output windows for the VUV lamp. The third port has a $\mathrm{KBr}$ window for the IR beam of the FTIR spectrometer. The input for the VUV lamp is placed with an angle of incidence $\sim 45^{\circ}$ to the mirror surface and, according to the estimates of the manufacturer, $\mathrm{MgF}_{2}$ transmits about $60 \%$ of the quantum flux at the wavelength of $121.6 \mathrm{~nm}$. As a VUV source (Lyman- $\alpha$ ) we use a resonance hydrogen lamp (Opthos Instruments) containing a mixture of $10 \% \mathrm{H}_{2}$ and $90 \% \mathrm{Ar}$, which is excited by a microwave generator (Opthos Instruments, model MPG-4M) with a frequency of $2450 \mathrm{MHz}$. The intensity of the lamp is determined by the power supplied by the microwave generator. The FTIR spectrometer is placed on rails allowing precise positioning of the instrument with respect to the cryostat with the sample. This is important in order to achieve a good overlap of the areas of the light spots from both, infrared (from spectrometer light source) and vacuum ultraviolet irradiation (from VUV lamp) of the ice film sample on the substrate. The overlap can be checked through the windows in the vacuum chamber. The operation of the FTIR spectrometer is PC controlled by means of software (OPUS) that permits scanning spectra over a wide range (from 6000 to $500 \mathrm{~cm}^{-1}$ ) and analyzing the obtained spectra. The spectra are recorded with a spectral resolution 


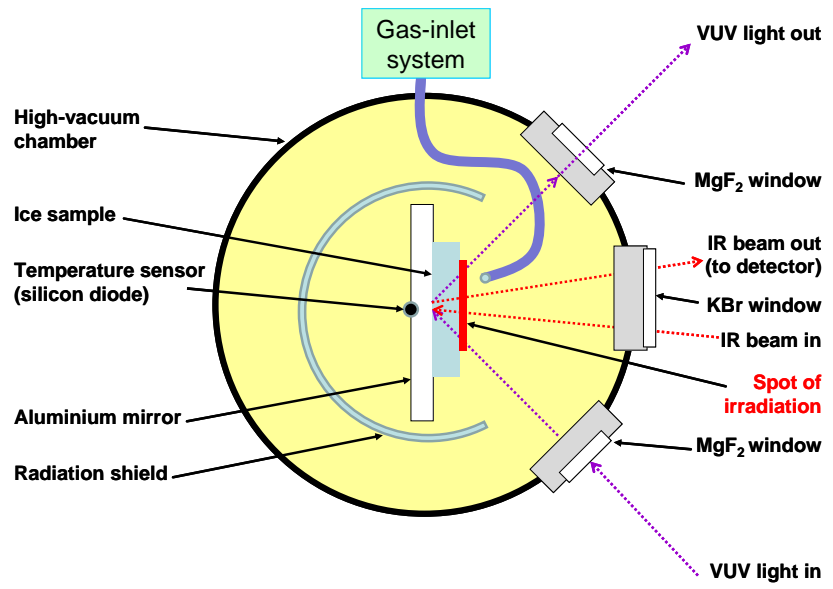

Fig. 1. Scheme of the laboratory setup illustrating the preparation of the ice film sample, its irradiation with VUV light by means of a hydrogen lamp and the measurement of IR spectra in the RAIRS mode.

of $0.2 \mathrm{~cm}^{-1}$ in the RAIRS mode (reflection absorption infrared spectroscopy) where the IR beam passes through the sample twice (see Fig. 1).

\subsection{Experimental procedures}

Every experiment with a particular sample of ice was conducted in two stages. At the first stage, a fixed mirror temperature was set by means of the temperature controller and the background spectrum was recorded. Then, an ice film was prepared by depositing water vapour onto the mirror. Velocity of the deposition and sample thickness were controlled by a needle valve of the gas-inlet system and by tracking the evolution of absorption bands in the FTIR spectra. Thickness and structure of the ice sample were monitored with the FTIR spectrometer using available data on intensities of $\mathrm{OH}$ stretching bands of water ice in the $3600-3000 \mathrm{~cm}^{-1}$ range. We prepared thin ice samples with characteristic thicknesses of 20-100 nm, which correspond to typical radii of NLC particles (e.g., von Cossart et al., 1999). The time of individual sample deposition varied within 1-3 min. After that, several IR spectra of unirradiated ice were recorded. In spite of the relatively fast velocity of deposition, the main features of these spectra demonstrated that all samples were crystalline (cubic) ice. It should be noted, that direct IR scanning of NLCs carried out by the ACE-FTS satellite instrument also showed that cloud particles were composed of crystalline ice (Eremenko et al., 2005).

At the second stage, the vacuum ultraviolet lamp was switched on and the ice films were exposed to VUV radiation. After each photolysis IR spectra of the irradiated ice films were recorded. Comparison of these spectra with the spectra obtained before irradiation allowed analyzing the influence of vacuum ultraviolet radiation on the water ice samples.

\subsection{Calibration of the hydrogen discharge lamp}

It is well known that the ultraviolet flux given by a microwave powered discharge lamp strongly depends on the operating conditions and can vary in the $10^{12}-10^{15}$ photons $\mathrm{cm}^{-2} \mathrm{~s}^{-1}$ range (Leto and Baratta, 2003). Based on this, we performed a series of measurements of the absolute magnitude of the flux of Lyman- $\alpha$ photons that reach the ice sample at different adjustments of the microwave generator power. For this procedure we applied the "ozone method" (e.g., Gerakines et al., 2000; Leto and Baratta, 2003; Schriver et al., 2004). The intensity of the lamp was determined by measuring the $\mathrm{O}_{2} \rightarrow \mathrm{O}_{3}$ conversion rate in a VUV photolyzed sample of solid $\mathrm{O}_{2}$ at $16 \mathrm{~K}$. For ensuring absorption by the sample of almost all incoming Lyman- $\alpha$ photons we prepared $\mathrm{O}_{2}$ layers with a thicknesses of about $1-2 \mu \mathrm{m}$.

The ozone formation as a function of photolysis time was monitored with the FTIR spectrometer via the $v_{3}$ absorption band at about $1040 \mathrm{~cm}^{-1}$. Appearance of new narrow absorption lines near $1040 \mathrm{~cm}^{-1}$ soon after the beginning of irradiation signals formation of ozone (see Fig. 2), and growth of the amplitude of this bands with time is a consequence of the increase of the concentration of this constituent. The observed ozone absorption band at about $1040 \mathrm{~cm}^{-1}$ has a complex fine structure with several maxima (see Fig. 2). One can see 8 pronounced maxima $\left(1042 \mathrm{~cm}^{-1}, 1039.8 \mathrm{~cm}^{-1}, 1037.7 \mathrm{~cm}^{-1}, 1034.3 \mathrm{~cm}^{-1}\right.$, $1032.6 \mathrm{~cm}^{-1}, 1031.1 \mathrm{~cm}^{-1}, 1030.2 \mathrm{~cm}^{-1}$, and $1029.6 \mathrm{~cm}^{-1}$ ) and 5 comparatively weak maxima. The positions of all the 13 maxima and their amplitude ratio are independent of the generator power and duration of irradiation. Dyer et al. (1997) in their work analysed the ozone absorption line arising in a sample of solid molecular oxygen as a result of laser irradiation with variable wavelength in the range 210 $250 \mathrm{~nm}$ and they showed that the appearance of the complex structure of ozone absorption band is associated with the formation of ozone dimmers. However, different trapping sites of the ozone species within the lattice of solid oxygen have to be considered as well.

For finding the radiation intensity of the lamp for a specific generator power we made a series of successive measurements of the integrated area of the $1040 \mathrm{~cm}^{-1}$ absorption band multiplet $(S)$ as a function of irradiation time. After that, the lamp intensity was determined from the following relation

$I=\frac{d S}{d t} /\left(Y \cdot S_{0}\right)$,

where the derivative $\frac{d S}{d t}$ is found by the linear part of the function $S(t) . \quad Y$ is the quantum yield for the formation of $\mathrm{O}_{3}$ from $\mathrm{O}_{2}$, and $S_{0}$ is the intensity of the ozone bands at $1040 \mathrm{~cm}^{-1}$. The value of $Y \cdot S_{0}$ was adopted from the study of Cottin et al. (2003) and is equal to $8.4 \times 10^{-18} \mathrm{~cm}$ photon $^{-1}$. Our measurements enabled us to ascertain that, depending on the generator output power 


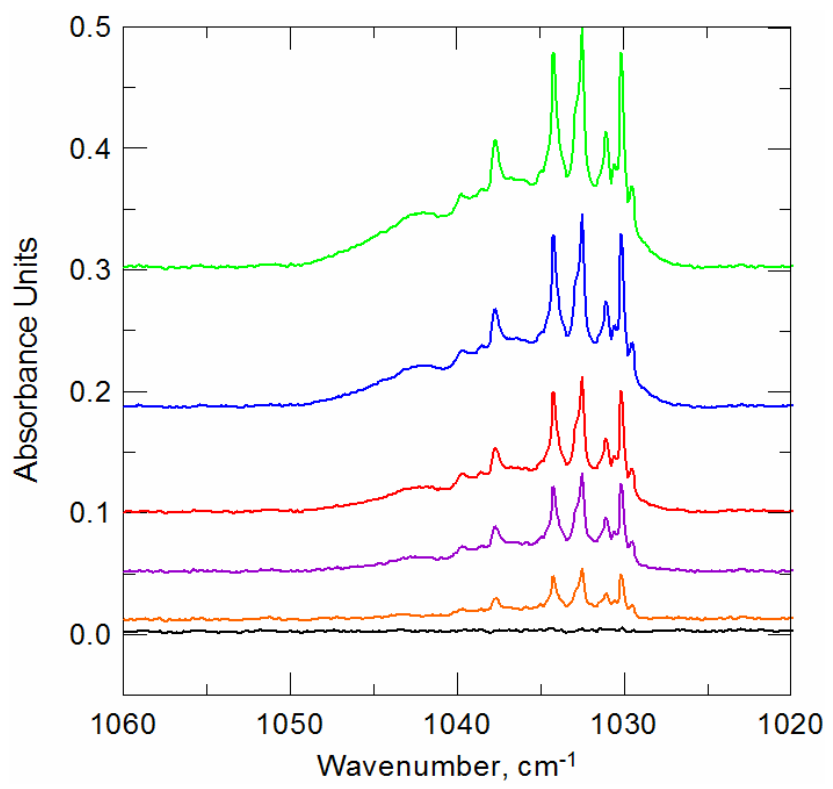

Fig. 2. Absorption spectra of solid molecular oxygen at $T=16 \mathrm{~K}$ before irradiation (black line) and after $1 \mathrm{~min}$ (orange), $6 \mathrm{~min}$ (purple), $16 \mathrm{~min}$ (red), $26 \mathrm{~min}$ (blue) and $79 \mathrm{~min}$ (green) of irradiation with the resonance hydrogen lamp (at a microwave generator power output of $30, \mathrm{~W}$ ) showing the growth of the $\mathrm{O}_{3}$ band multiplet in the $1040-1030 \mathrm{~cm}^{-1}$ range.

$(4-100 \mathrm{~W})$, the photon flux intensity varies within the range $5 \times 10^{12}-10^{14}$ photons $\mathrm{cm}^{-2} \mathrm{~s}^{-1}$. For a power less than $4 \mathrm{~W}$, discharge generation in a VUV lamp becomes unstable.

\section{Measurements of the photodesorption rates from thin water ice samples}

The experiments and further analysis of the results were carried out under the following assumptions:

1. The column density of thin $(20-100 \mathrm{~nm})$ samples of water ice films is related linearly to the integrated area of the band with a maximum at about $3275 \mathrm{~cm}^{-1}$ (hereinafter $S$ ) of the IR absorption of water ice. The intensity of the absorption band (hereinafter $S_{0}$ ) is known from the literature (Allamandola et al., 1988). No phase transition of water ice samples to hexagonal or amorphous ice was registered during irradiation, as was found, for example, by Leto and Baratta (2003). So, the value of $S_{0}$ can be considered to be constant. Therefore, by successive measurements of the principal absorption band of water it is possible to control the magnitude of the column density $N=S / S_{0}$. For example, for the ice sample thickness of $100 \mathrm{~nm}, N \sim 3 \times$ $10^{17}$ molecules $\mathrm{cm}^{-2}, S \sim 60 \mathrm{~cm}^{-1}$.

2. Additional uncontrolled condensation of $\mathrm{H}_{2} \mathrm{O}$ molecules on the mirror occurs $\left(\mathrm{H}_{2} \mathrm{O}\right.$ desorption from the warmer walls of the vacuum chamber) during the lifetime of an ice sample at high temperatures $(120-150 \mathrm{~K})$, giving rise to monotonic increase of the values of $S$ and $N$.

3. As follows from the results of laboratory studies of low-temperature $(10-20 \mathrm{~K})$ ice photolysis, Lyman- $\alpha$ irradiation causes a wide spectrum of physical and chemical processes in the ice (Gerakines et al., 1996; Schriver et al., 2004). Firstly, the reaction $\mathrm{H}_{2} \mathrm{O}+h v$ $(121.6 \mathrm{~nm})$ may have an additional channel $\mathrm{H}_{2}+\mathrm{O}$. Secondly, chemical reactions with formation of secondary products $\mathrm{H}_{2} \mathrm{O}, \mathrm{HO}_{2}, \mathrm{HO}_{3}, \mathrm{H}_{2} \mathrm{O}_{2}, \mathrm{O}_{2}, \mathrm{O}_{3}$ can take place between the primary photolysis products. Thirdly, the mobility of the photoproducts inside the ice (and, correspondingly, their conversion to gas phase) is determined by diffusion whose coefficient strongly depends on the chemical composition of the species and the temperature. At relatively high temperatures of order $100 \mathrm{~K}$ and higher, nearly all primary and secondary photoproducts (except $\mathrm{H}_{2} \mathrm{O}$ and $\mathrm{H}_{2} \mathrm{O}_{2}$ ) are extremely mobile. Specifically, the value of atomic hydrogen diffusivity $D_{\mathrm{H}}$ in water ice at temperatures of $120-150 \mathrm{~K}$ varies within the $\sim 10^{-12}-10^{-11} \mathrm{~m}^{2} \mathrm{~s}^{-1}$ range (Bartels et al., 1992). The diffusion time for the escape of this photoproduct into the gas phase from an ice sample with thickness $L=100 \mathrm{~nm}$ is readily estimated to be $L^{2} \cdot D_{\mathrm{H}}^{-1} \sim 10^{-3}-10^{-2} \mathrm{~s}$. Thus, considering that hydrogen peroxide formation is a relatively slow process even at high temperatures, we come to the following conclusions:

Firstly, recovery of $\mathrm{H}_{2} \mathrm{O}$ molecules (primarily as a result of $\mathrm{H}+\mathrm{OH}$ recombination) is the basic process limiting the rate of photodesorption from water ice samples. Secondly, irreversible photodissociation of water molecules in irradiated ice will lead to a proportional decrease of the integrated area of the $3275 \mathrm{~cm}^{-1}$ band, so that the rate of column density decrease under exposure to VUV radiation will correlate with the rate of photodesorption from the water ice sample. In particular, in the case addressed by Murray and Plane (2005), absorption of a definite amount of Lyman- $\alpha$ photons over a certain period of irradiation leads to the same change of column density.

In accord with the above enumerated observations, each experiment with a separate sample at a specific temperature (in the $120-150 \mathrm{~K}$ intervals) was carried out in two stages. At the first stage, a thin sample was formed, after which its IR spectrum was regularly recorded without irradiation for quite a long time (about two hours). This enables determining the rate of the uncontrolled growth of column density. At the second stage, the VUV lamp was turned on and IR spectra were recorded repeatedly over a long time interval. The irradiation was performed at maximum generator power, so that the lamp intensity I was about $6 \times 10^{15}$ photons $\mathrm{cm}^{-2} \mathrm{~min}^{-1}$ in all the experiments. Thus, 

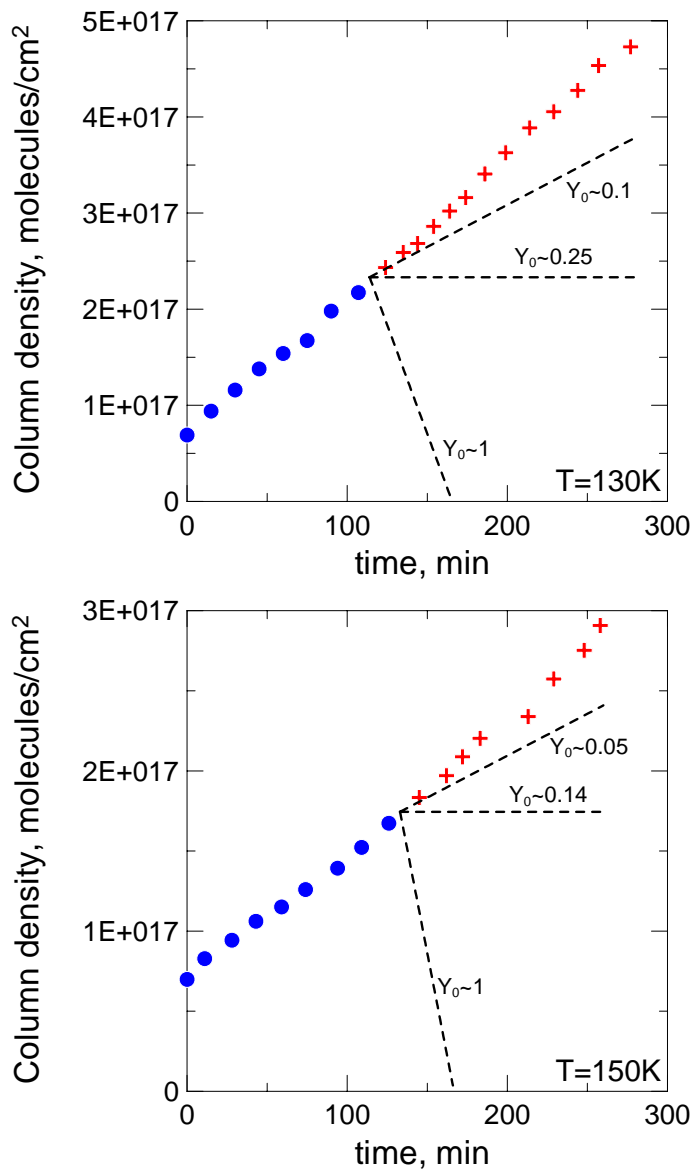

Fig. 3. Time evolution of column density at different temperatures before irradiation (blue points) and after switching on VUV lamp (red crosses). The dashed black lines indicate asymptotic trends of the column density corresponding to different theoretical values of absolute photodesorption yield (in molecule photon ${ }^{-1}$ ).

if photodesorption is an essential process (the absolute photodesorption yield $Y_{0} \sim 1$ molecule photon ${ }^{-1}$ ), then the lifetime of thin $(20-100 \mathrm{~nm})$ water ice samples should not be longer than 50-100 min. At least, we expected to obtain a break of the time curve of column density when starting VUV irradiation.

Nevertheless, the conducted experiments demonstrated that the photodesorption rates from thin water ice samples were very small for all values of temperature in the 120 $150 \mathrm{~K}$ interval (see Fig. 3). All the obtained functions $N(t)$ were monotonic, without pronounced breaks at the start of irradiation. Average (over one experiment) values of column density growth rates $d N / d t$ were much less than the lamp intensity, indicating that the absolute photodesorption yield $Y_{0}$ must be much less than 1 molecule photon ${ }^{-1}$. At $T=$ $130 \mathrm{~K}$, the rate of uncontrolled growth of sample thickness is $\sim 1.5 \times 10^{15}$ molecules $\mathrm{cm}^{-2} \mathrm{~min}^{-1}$, whereas at higher temperature $(T=150 \mathrm{~K})$ the average value of this rate is still lower: $\sim 8.6 \times 10^{14}$ molecules $\mathrm{cm}^{-2} \mathrm{~min}^{-1}$. The absence of a break in $N(t)$ gives the following estimate for the absolute photodesorption yield $Y_{0} \ll d N / d t \cdot I^{-1}$, from which follows that in the presented examples $Y_{0} \ll 0.25$ molecule photon ${ }^{-1}$ at $130 \mathrm{~K}$ and $Y_{0} \ll 0.14$ molecule photon $^{-1}$ at $150 \mathrm{~K}$. Moreover, the presented plots include the asymptotic trends of the column density corresponding to different theoretical values of absolute photodesorption yield. To compare the trends with experimental behaviour of the column density it can be concluded that real experimental values of $Y_{0}$ are essentially less than $0.05-0.1$ molecule photon $^{-1}$ in both cases.

\section{Discussion and conclusion}

The conducted experiments demonstrate that retrieval of $\mathrm{H}_{2} \mathrm{O}$ molecules almost fully suppresses photodesorption from a thin water ice sample at the temperatures of 120 $150 \mathrm{~K}$. The absorption cross-section $(\sigma)$ of Lyman- $\alpha$ of photons in ice is known to be $\sim 8 \times 10^{-18} \mathrm{~cm}^{2}$ (Westley et al, 1995a) and is only weakly temperature dependent. Therefore, the characteristic time of VUV photodissociation of a specific water molecule (and hence, formation of $\mathrm{H}$ and $\mathrm{OH}$ products at this point) with the lamp intensity $I=$ $10^{14}$ photons $\mathrm{cm}^{-2} \mathrm{~s}^{-1}$ may be assessed to be $\tau \geq(\sigma I)^{-1} \sim$ $10^{3} \mathrm{~s}$. Note that this time is at least 5-6 orders of magnitude higher than the diffusion time of atomic hydrogen escaping into gas phase (see Sect. 3). Consequently, for the explanation of the results obtained we can assume that $\mathrm{H}_{2} \mathrm{O}$ molecules are retrieved within the bulk mainly as a result of $\mathrm{H}+\mathrm{OH}$ recombination reaction that follows immediately after photodissociation of $\mathrm{H}_{2} \mathrm{O}$, so that photoproducts do not have sufficient time to escape from the lattice site where they were born. However, directly at the surfaces of the ice particles the situation might be different due to different intermolecular hydrogen bonding interactions (Ignatov et al., 2009).

Note that under real mesopause conditions, the intensity of the Lyman- $\alpha$ radiation is approximately $(2-6) \times$ $10^{11}$ photons $\mathrm{cm}^{-2} \mathrm{~s}^{-1}$, depending on the height and solar activity, which is more than two orders of magnitude lower than the intensity of our hydrogen lamp. Thus, summarizing of the obtained results leads to the conclusion that photodesorption from NLCs particles seems to be an absolutely insignificant process in the photochemistry of the upper mesosphere. Almost all the photoproducts are expected to remain in the solid phase after photolysis, and the principal chemical reaction between them is the recombination $\mathrm{H}+\mathrm{OH} \rightarrow \mathrm{H}_{2} \mathrm{O}$ which is evidently very fast.

Acknowledgements. The work was performed with support by the DAAD (German Academic Exchange Service) with the fellowship (study visits) and eastpartnership programmes as well as by the RFBR (project 10-05-01112) and Russian Federal Special Program "Scientific and scientifically-pedagogical staff of innovative Russia" in 2009-2013 (contact P2318).

Edited by: F.-J. Lübken 


\section{References}

Allamandola, L. J., Sandford, S. A., and Valero, G. J.: Photochemical and Thermal Evolution of Interstellar/Precometary Ice Analogs, Icarus, 76, 225-252, 1988.

Bartels, D. M., Han, P., and Percival, P. W.: Diffusion and CIDEP of $\mathrm{H}$ and $\mathrm{D}$ atoms in solid $\mathrm{H}_{2} \mathrm{O}, \mathrm{D}_{2} \mathrm{O}$ and isotopic mixtures, Chem. Phys., 164, 421-437, 1992.

Brasseur, G. and Solomon, S.: Aeronomy of the Middle Atmosphere, 452 pp., D. Reidel, Norwell, Mass., 1986.

Cottin, H., Moore, M. H., and Bénilan, Y.: Photodestruction of relevant interstellar molecules in ice mixtures, Astroph. J., 590, 874$881,2003$.

Dyer, M. J., Bressler, C. G., Copeland, and R. A.: Photodissociation of solid oxygen with tunable ultraviolet laser light: ozone production monitored via Fourier-transform infrared spectroscopy, Chem. Phys. Lett., 266, 548-553, 1997.

Eremenko, M. N., Petelina, S. V., Zasetsky, A. Y., Karlsson, B., Rinsland, C. P., Llewellyn, E. J., and Sloan, J. J.: Shape and composition of PMC particles derived from satellite remote sensing measurements, Geophys. Res. Lett., 32, L16S06, doi:10.1029/2005GL023013, 2005.

Gadsden, M. and Schröder, W.: Noctilucent clouds, Springer Verlag, Berlin, 1989.

Gerakines, P. A., Schutte, W. A., and Ehrenfreund, P.: Ultraviolet processing in interstellar ice analogs. 1. Pure ices, A\&A, 312, 289-305, 1996.

Gerakines, P. A., Moore, M. H., and Hudson, R. L.: Carbonic acid production in $\mathrm{H}_{2} \mathrm{O}: \mathrm{CO}_{2}$ ices - $\mathrm{UV}$ photolysis vs. proton bombardment, A\&A, 357, 793-800, 2000.

Hama, T., Yokoyama, M., Yabushita, A., Kawasaki, M., and Andersson, S.: Desorption of hydroxyl radicals in the vacuum ultraviolet photolysis of amorphous solid water at $90 \mathrm{~K}$, J. Chem. Phys., 131, 054508, doi:10.1063/1.3191731, 2009a.

Hama, T., Yabushita, A., Yokoyama, M., Kawasaki, M., and Watanabe, N.: Formation mechanisms of oxygen atoms in the $\mathrm{O}\left({ }^{1} \mathrm{D}_{2}\right)$ state from the $157 \mathrm{~nm}$ photoirradiation of amorphous water ice at $90 \mathrm{~K}$, J. Chem. Phys., 131, 114510, doi:10.1063/1.3194798, 2009b.

Hama, T., Yabushita, A., Yokoyama, M., Kawasaki, M., and Watanabe, N.: Formation mechanisms of oxygen atoms in the $\mathrm{O}\left({ }^{3} \mathrm{P}_{J}\right)$ state from the $157 \mathrm{~nm}$ photoirradiation of amorphous water ice at $90 \mathrm{~K}, \mathrm{~J}$. Chem. Phys., 131, 114511, doi:10.1063/1.3194797, 2009c.

Hama, T., Yokoyama, M., Yabushita, A., Kawasaki, M., Andersson, S., Western, C. M., Ashfold, M. N. R., Dixon, R. N., and Watanabe, N.: A desorption mechanism of water following vacuumultraviolet irradiation on amorphous solid water at $90 \mathrm{~K}$, J. Chem. Phys., 132, 164508, doi:10.1063/1.3386577, 2010.

Hervig, M., Thompson, E., McHugh, M., Gordley, L., Russell III, J., and Summers, M. E.: First confirmation that water ice is the primary component of polar mesospheric clouds, Geophys. Res. Lett., 28, 971-974, 2001.

Ignatov, S. K., Razuvaev, A. G., Sennikov, P. G. and Schrems, O.: $\mathrm{H}_{2} \mathrm{O}_{2}$ adsorption on the ice $\mathrm{I}_{h}$ surface, Theoretical study with systematic assessment of the orientation isomerism of the hydrogen bond network, J. Mol. Struct. THEOCHEM, 908, 47-54, 2009.
Jesse, O.: Auffallende Abenderscheinungen am Himmel, Meteorol. Z, 2, 311-312, 1885 .

Leto, G. and Baratta, G.A.: Ly- $\alpha$ photon induced amorphization of $\mathrm{I}_{c}$ water ice at 16 Kelvin Effects and quantitative comparison with ion irradiation, A\&A, 397, 7-13, 2003.

Lübken, F. J.: Thermal structure of the Arctic summer mesosphere, J. Geophys. Res.-Atmos., 104, 9135-9149, 1999.

Murray, B. J. and Plane, J. M. C.: Modelling the impact of noctilucent cloud formation on atomic oxygen and other minor constituents of the summer mesosphere, Atmos. Chem. Phys., 5, 1027-1038, doi:10.5194/acp-5-1027-2005, 2005.

Schriver, A., Coanga, J. M., Schriver-Mazzuoli, L., and Ehrenfreund, P.: FTIR studies of ultraviolet photo-dissociation at $10 \mathrm{~K}$ of dimethyl ether in argon and nitrogen matrices, in the solid phase and in amorphous water ice, Chem. Phys. Lett., 386, 377-383, 2004.

Thayer, J. P., Thomas, G. E., and Lübken, F.-J.: Foreword: Layered phenomena in the mesopause region, J. Geophys. Res., 108(D8), 8434, doi:10.1029/2002JD003295, 2003.

Thomas, G. E.: Mesospheric clouds and the physics of the mesopause region, Rev. Geophys., 29, 553-575, 1991.

Thomas, G. E., Olivero, J. J., Jensen, E. J., Schröder, W. , and Toon O. B.: Relation between increasing methane and the presence of ice clouds at the mesopause, Nature, 338, 490-492, 1989.

von Cossart, G., Fiedler, J., and von Zahn, U.: Size distributions of NLC particles as determined from 3-color observations of NLC by ground-based lidar, Geophys. Res. Lett., 26, 1513-1516, 1999.

von Zahn, U. and Berger, U.: Persistent ice cloud in the midsummer upper mesosphere at high latitudes: Three-dimensional modeling and cloud interactions with ambient water vapor, J. Geophys. Res.-Atmos., 108, 8451, doi:10.1029/2002JD002409, 2003.

Warren, S.: Optical constants of ice from the ultraviolet to the microwave, Appl. Optics, 23, 1206-1225, 1984.

Watanabe, N., Horii, T., and Kouchi, A.: Measurements of $\mathrm{D}_{2}$ yields from amorphous $\mathrm{D}_{2} \mathrm{O}$ ice by ultraviolet irradiation at $12 \mathrm{~K}$, Astrophys. J., 541, 772-778, 2000.

Wegener, A.: Die Erforschung der obersten Atmosphärenschichten, Gerlands Beitr. Geophys., 11, 102-124, 1912.

Westley, M. S., Baragiola, R. A., Johnson, R. E., and Baratta, G. A.: Ultraviolet photodesorption from water ice, Planet. Space Sci., 43(10/11), 1311-1315, 1995a.

Westley, M. S., Baragiola, R. A., Johnson, R. E., and Baratta, G. A.: Photodesorption from low-temperature water ice in interstellar and circumsolar grains, Nature, 373, 405-407, $1995 \mathrm{~b}$.

Yabushita, A., Hama, T., Iida, D., Kawanaka, N., Kawasaki, M., Watanabe, N., Ashfold, M. N. R., and Loock, H.-P.: Release of hydrogen molecules from the photodissociation of amorphous solid water and polycrystalline ice at 157 and $193 \mathrm{~nm}$, J. Chem. Phys., 129, 044501, doi:10.1063/1.2953714, 2008a.

Yabushita, A., Hama, T., Iida, D., Kawanaka, N., Kawasaki, M., Watanabe, N., Ashfold, M. N. R., and Loock, H.-P.: Measurements of energy partitioning in $\mathrm{H}_{2}$ formation by photolysis of amorphous water ice, Astrophys. J. Lett., 682, L69-L72, 2008 b. 